\title{
Three-Dimensional Organization of Smooth Endoplasmic Reticulum in Hippocampal CA1 Dendrites and Dendritic Spines of the Immature and Mature Rat
}

\author{
Josef Spacek ${ }^{1}$ and Kristen M. Harris ${ }^{2}$ \\ ${ }^{1}$ Department of Pathology, Charles University Medical Faculty Hospital, CZ-500 05 Hradec Kralove, Czech Republic, and \\ 2Division of Neuroscience, Children's Hospital and Harvard Medical School, Boston, Massachusetts 02115
}

Recent studies have shown high levels of calcium in activated dendritic spines, where the smooth endoplasmic reticulum (SER) is likely to be important for regulating calcium. Here, the dimensions and organization of the SER in hippocampal spines and dendrites were measured through serial electron microscopy and three-dimensional analysis. SER of some form was found in $58 \%$ of the immature spines and in $48 \%$ of the adult spines. Less than $50 \%$ of the small spines at either age contained SER, suggesting that other mechanisms, such as cytoplasmic buffers, regulate ion fluxes within their small volumes. In contrast, $>80 \%$ of the large mushroom spines of the adult had a spine apparatus, an organelle containing stacks of SER and dense-staining plates. Reconstructed SER occupied $0.001-0.022 \mu \mathrm{m}^{3}$, which was only $2-3.5 \%$ of the total spine volume; however, the convoluted SER membranes had surface areas of $0.12-2.19 \mu \mathrm{m}^{2}$, which were 12 to $40 \%$ of the spine surface area. Coated vesicles and multivesicular bodies occurred in some spines, suggesting local endocytotic activity. Smooth vesicles and tubules of SER were found in continuity with the spine plasma membrane and margins of the postsynaptic density (PSD), respectively, suggesting a role for the SER in the addition and recycling of spine membranes and synapses. The amount of SER in the parent dendrites was proportional to the number of spines and synapses originating along their lengths. These measurements support the hypothesis that the SER regulates the ionic and structural milieu of some, but not all, hippocampal dendritic spines.

Key words: dendritic spines; smooth endoplasmic reticulum; hippocampus; serial sections; three-dimensional reconstructions; spine apparatus; synapse; postsynaptic density; calcium; coated vesicles; multivesicular bodies; endocytosis; exocytosis
The neuronal endoplasmic reticulum (ER), like that in most non-neuronal cells, represents a principal part of the inner membrane system (Alberts et al., 1983; Broadwell and Cataldo, 1983, 1984; Lindsey and Ellisman, 1983a,b,c; Peters et al., 1991; Villa and Meldolesi, 1994). In this system, the granular or rough endoplasmic reticulum is usually associated with ribosomes and synthesizes proteins and lipids. Transitional elements including the Golgi complex, smooth endoplasmic reticulum (SER), and endocytotic and exocytotic shuttle vesicles are involved in the transfer and export of membrane material, enzymes, and secretory vesicles. The end products of the internal membrane system include the plasma membrane, synaptic and other secretory vesicles, mitochondria, peroxisomes, lysosomes, vacuoles, and other membrane-bound organelles. In the nerve cell body and proximal dendrites, the rough endoplasmic reticulum is prominent, whereas in the distal parts of dendrites and dendritic spines, the SER predominates. In various cells of different tissues, the SER is thought to play important roles in the regulation of calcium and chloride ions; in the transport of lipids and circulation of mem-

Received Aug. 5, 1996; revised Oct. 4, 1996; accepted Oct. 14, 1996.

This work was supported by National Institutes of Health (NIH)/Fogarty International Center Grant TW00178, NIH Grants NS21184 and NS33574, and Medical Research Center Grant P30-HD18655. We thank Dr. John Davis, Dr. John Fiala, and Rajesh Jathar for their assistance on the reconstruction systems in the Image Graphics laboratory at Children's Hospital. We also thank Drs. Steve Finkbeiner and John Fiala for their thoughtful input.

Correspondence should be addressed to Kristen M. Harris, Ph.D., Division of Neuroscience, Enders 260, Children's Hospital, 300 Longwood Avenue, Boston, MA 02115.

Copyright (C) 1996 Society for Neuroscience $\quad 0270-6474 / 96 / 170190-14 \$ 05.00 / 0$ brane phospholipids and glycoproteins; in the metabolism of lipids, lipoproteins, and glycogen; in the synthesis of steroid hormones; and in detoxification (Ghadially, 1982).

In neuronal dendrites, the regulation of calcium and transport of materials constituting the plasma membrane and synapses are likely to be the most crucial functions of the SER (Fifkova et al., 1983; Broadwell and Cataldo, 1984; Villa and Meldolesi, 1994). From a continuous network in the dendritic shafts, extensions of SER enter dendritic spines and form a single tubule in some or a specialized cisternal derivative called the spine apparatus in others (Gray, 1959; Peters et al., 1991). It has long been known that dendritic spines come in rather distinct classes based on their shapes (stubby, thin, mushroom, and branched) as well as on the character of their synapse and subcellular organelles (Jones and Powell, 1969; Peters and Kaiserman-Abramof, 1970; Peters et al., 1991). Previous studies in cerebellum and visual cortex have also shown a good correlation between the dimensions of SER and the dimensions of dendritic spines or synapses (Spacek and Hartmann, 1983; Harris and Stevens, 1988; Martone et al., 1993). Functional subcompartments of the ER system also have a heterogeneous distribution of specific receptors, pumps, and markers for different parts of the protein synthesis and transport pathways (Takei et al., 1992; Krijnse-Locker et al., 1995). Together, these observations suggest that different spine types might perform different subcellular functions depending on their subcellular composition.

The present study was motivated by the current intense efforts to understand the mechanisms of calcium regulation during synaptic transmission, synaptic plasticity, and second messenger sig- 

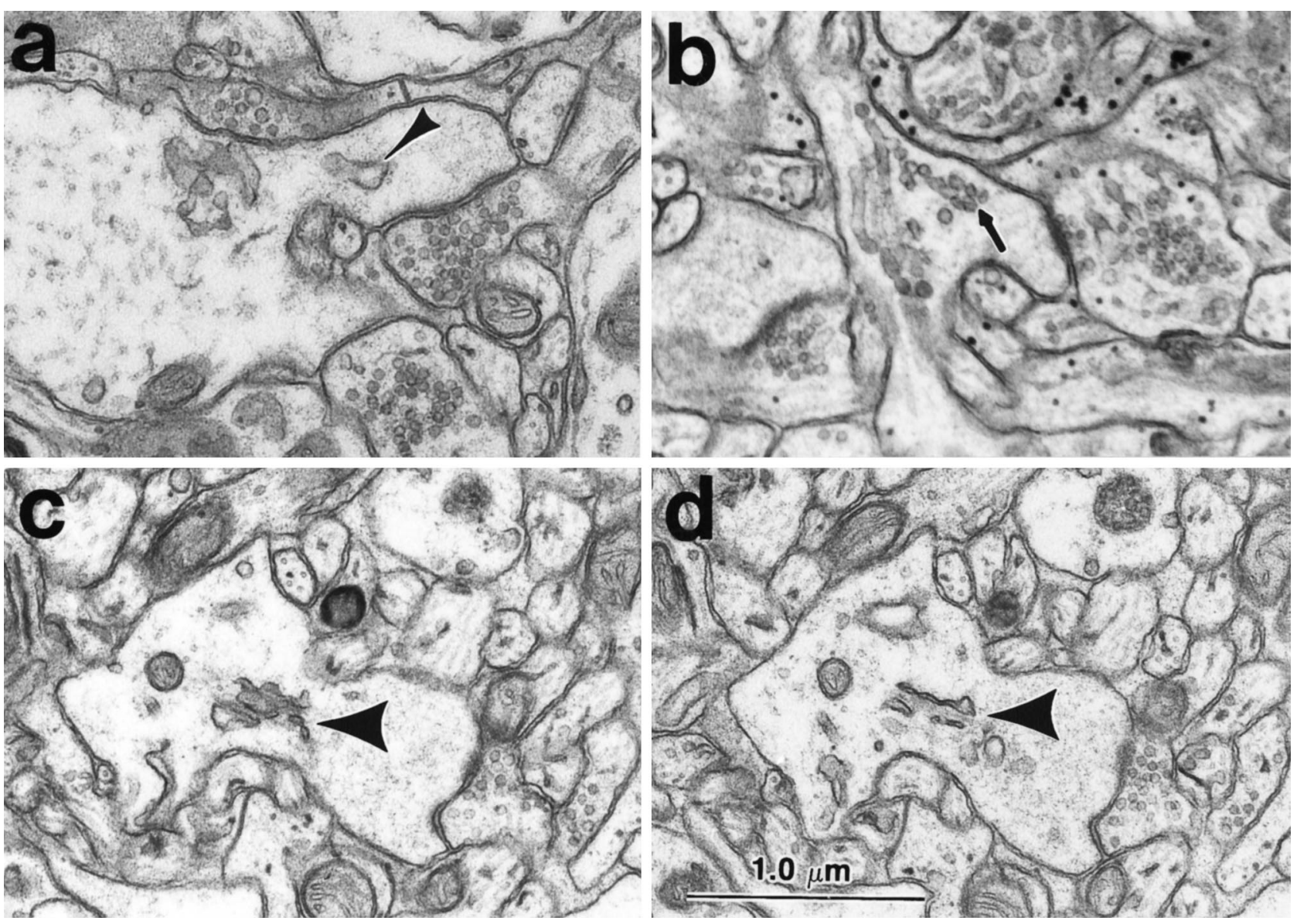

Figure 1. SER and spine apparatus in dendritic spines of hippocampal area CA1 at postnatal day 15. $a$, Cistern of SER (arrowhead) and $b$, vesicles of SER (arrow) in stubby dendritic spines. (This image is a bit soft, because it was enlarged from the edge of a negative that was photographed at $4 \mathrm{~K}$.) $c$, $d$, Adjacent serial sections through a spine apparatus (short thick arrow) in an emerging stubby-shaped dendritic spine with a perforated PSD on the spine head. It is likely that this spine represents the precursor of mushroom-shaped spines in the adults. Scale bar (shown in $d$ ): $1.0 \mu \mathrm{m}$.

naling and in the pathophysiology of glutamate toxicity (Guthrie et al., 1991; Muller and Connor, 1991; Choi, 1995; Clapham, 1995; Murphy et al., 1995; Petrozzino et al., 1995; Rosen et al., 1995; Yuste and Denk, 1995; Segal, 1995a,b; Svoboda et al., 1996; Yuste and Tank, 1996). Although many of the functional studies have been conducted on hippocampal CA1 neurons, to our knowledge, no three-dimensional or quantitative studies of the SER have been done in this brain region. Hence, the goal of this study was to provide a quantitative analysis of the SER in dendritic spines and the parent dendrites as a basis for understanding how this organelle could be involved in the elevation and regulation of calcium at hippocampal synapses. Preliminary results have been presented in abstract form elsewhere (Harris and Spacek, 1995).

\section{MATERIALS AND METHODS}

Tissue processing. Serial electron micrographs (EM) were obtained in an earlier study from the middle of stratum radiatum in hippocampal area CA1 (Harris and Stevens, 1989; Harris et al., 1992). Three male rats of the Long-Evans strain, two aged between postnatal day 14-15 (referred to as day 15) and one $\sim 77$ days old (referred to as adult), were used in this study. Briefly, an intracardiac perfusion was performed under deep pentobarbital anesthesia, with fixative containing $2 \%$ paraformaldehyde,

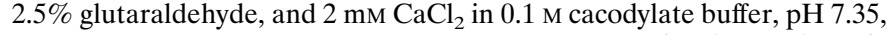
$37^{\circ} \mathrm{C}$, and 4 psi backing pressure from compressed gas $\left(95 \% \mathrm{O}_{2} / 5 \% \mathrm{CO}_{2}\right)$, and then processed by our standard protocols for transmission electron microscopy at a JEOL 1200EX electron microscope (Harris and Stevens, 1989; Harris et al., 1992; Harris, 1994). A combination of uranyl acetate and lead citrate applied to the grids enhanced the staining of dense plates and postsynaptic densities (PSDs); however, this combination of grid stains was also prone to random areas of splotchy precipitate on the sections. As a compromise, lead staining alone was used on the serial sections that were analyzed quantitatively, including a total of three sets of serial sections from day 15 and two sets from the young adult. These were supplemented with shorter series having both grid stains for selective photography and to confirm observations made with lead staining alone.

Chemical substances and several pathological conditions are associated with variation in the appearance of the SER (Ghadially, 1982). Thus, the dilation, vesiculation, and elaboration of the SER may reflect variation in the functional state of specific dendritic spines and their synapses. The SER is also one of the membranous organelles most sensitive to variation in preparation. Its tubules may be artificially dilated or broken into vesicles due to mechanical damage or hypotonic fixation; hence, care was exercised to handle the tissue gently during all stages of processing, and the fixative was slightly hypertonic. In addition, we used a mixture of buffered osmic acid and potassium ferrocyanide to obtain optimal preservation of membranes (Karnovsky, 1971; Langford and Coggeshall, 1980). Our observations were made in brains that were perfused within 30 sec after death, suggesting that the spine apparatus is different from the stacks of SER observed in Purkinje cells when prolonged periods (8 min) of hypoxia precede perfusion (Takei et al., 1994).

Criteria for including and classifying dendritic spines in the unbiased sample populations. All dendritic spines with their PSDs occurring on a central, reference section of each series were included in the day 15 and adult samples (See Harris et al., 1992). Dendritic spines were viewed through serial sections and classified according to Peters and KaisermanAbramof (1970) into the four shape categories of thin, mushroom, stubby, and branched spines. Spines were considered thin if their length was greater than the neck diameter, and the diameters of the head and neck 

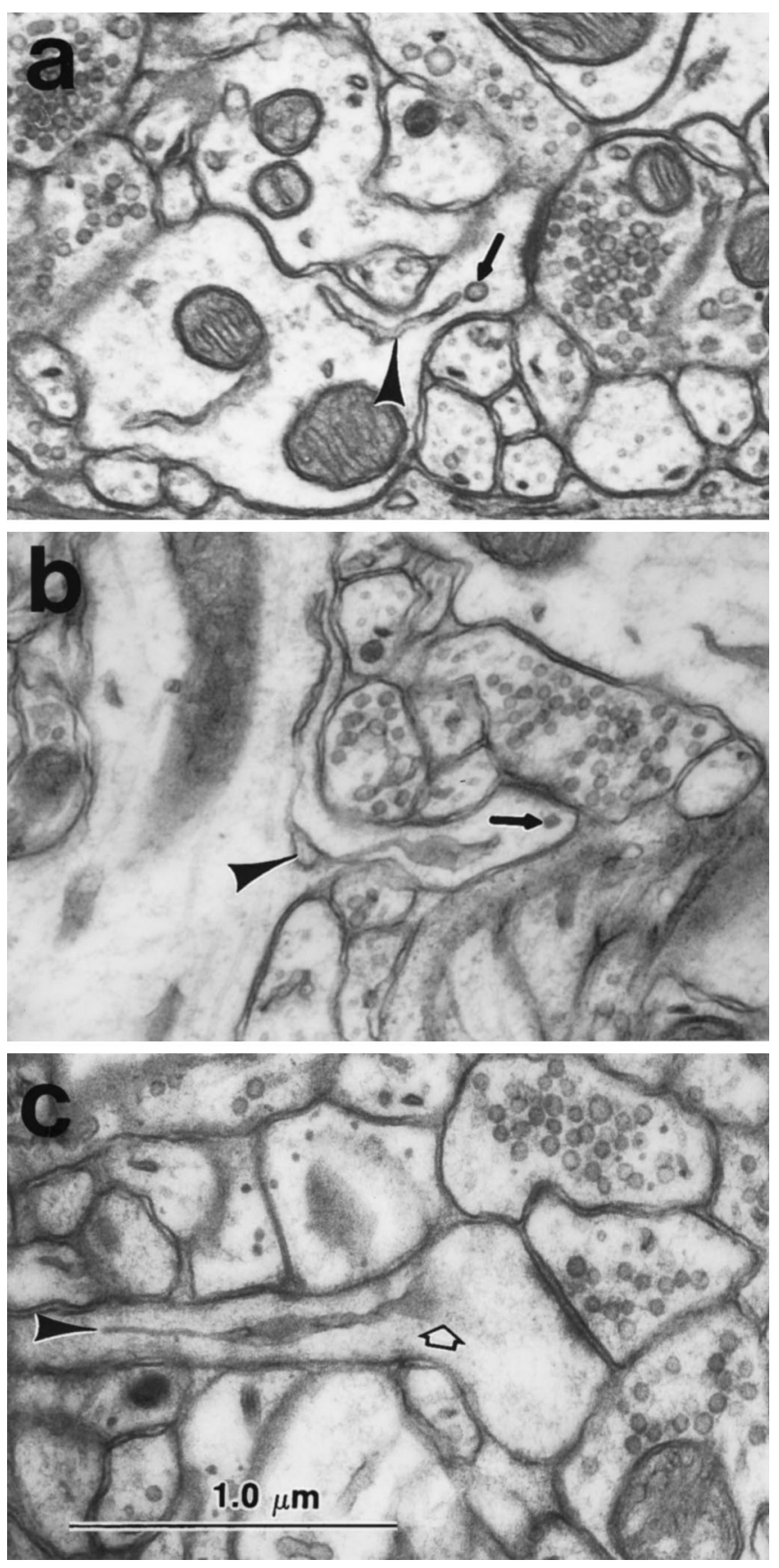

Figure 2. Tubules and vesicles of SER in thin dendritic spines of the adult hippocampus (CA1). a, Cistern of SER (arrowhead) entering from the dendritic shaft into a short spine with a thin neck and ending at a free vesicle of SER (arrow) in the spine head. $b$, Cistern of SER (arrowhead) in the neck of a thin spine and free smooth vesicle (arrow) in the spine head. $c$, Thin tubule of SER (arrowhead) ending in a flat cistern (open arrow) in the spine head. Scale bar (shown in $c$ ): $1.0 \mu \mathrm{m}$.

were similar. For mushroom-shaped spines, the diameter of the head was much greater than the diameter of the neck. Stubby spines had neck diameters that were similar to the total spine length. Branched spines had more than one head emerging from a single neck originating from the dendrite.

Three-dimensional reconstructions and computations. Serial EMs, or outlines of structures redrawn from them, were placed under a video camera, and their images were captured in a PC-based frame grabber (Vision-8, Insync Technologies, San Leandro, CA). The images were microaligned by rapid switching between the stored and "live" images of adjacent sections, and then outlines of the plasma membrane, postsynaptic densities, mitochondria and SER were traced and morphometric data were determined using PC-based software developed at the Children's Hospital Image Graphics Laboratory. Section thickness was determined previously, and volumes, surface areas, and lengths were computed with the V8 software as described in Harris and Stevens, 1989; Harris et al., 1992; and Harris, 1994. Three-dimensional visualization of dendritic spines and their associated SER, spine apparatuses, and in some cases, dendritic segments was achieved with ICAR software (ISG Technologies, Ontario, Canada) or a PC-based Design CAD-3D software system (American Small Business Computers) (Spacek, 1994). The threedimensional reconstructions from serial EMs enabled us to obtain a detailed analysis of SER distribution and to calculate volumes and surface areas as indicated in Results.

\section{RESULTS}

\section{Ultrastructural appearance of the SER and spine apparatus}

The day 15 spines usually contained some cisterns or vesicles of SER (Fig. 1 $a, b)$. Rarely, a spine apparatus having two or more cisterns of SER laminated with a dense-staining material was found in a large stubby or mushroom-shaped dendritic spine with a perforated PSD (Fig. 1c,d).

In the adult hippocampus, different spines contained more or less SER depending on the spine size and shape. Thin tubules of SER turned from the dendritic shafts and entered thin dendritic spines where the SER either ended inside the neck or traversed the neck up into the spine head and ended in a tubule, one or more smooth vesicles (Fig. $2 a, b$ ), or a flat cistern (Fig. $2 c$ ). These thin spines typically had macular PSDs characterized by a continuous surface when viewed through serial sections (see below). Some segments of SER tubules were thinned down to the diameter of the microtubules (Fig. 2b,c), and they were detectable both by the darker appearance of the SER when compared with the microtubules and by the eventual connectivity of the SER tubule with the SER network of the parent dendrite.

A dendritic spine apparatus is distinguished by the lamination of cisterns or tubules of SER with dense staining material usually called the inner and outer dense plates. The mature dendritic spine apparatus was usually elaborated from a single narrow tubule of SER (Fig. $3 a$ ) that then branched to form two or more cisterns during its course along the neck or into the spine head (Fig. 3b). The large spines containing a spine apparatus had perforated PSDs, which are characterized by electron lucent regions separating portions of the PSD (Fig. $3 b, d, g$ ). The cisterns of the spine apparatus were separated by dense-staining material called dense plates (Fig. $3 b$ ). The length and diameter of the spine neck were related to the character of the spine apparatus, such that the shorter and wider the neck, the more proximal was the first branching point and dense plate of the spine apparatus. In some spines, the spine apparatus occupied much of the neck (Fig. $3 c$ ), whereas in others, a single tube traversed the neck and elaborated into a spine apparatus in the head of the spine (e.g., see Fig. 8 below). In some of the mushroom spine heads, the spine apparatuses were associated with a cluster of smooth vesicles (Fig. $3 d$ ). Mature spine apparatuses could also be observed beneath wide stubby spines with perforated PSDs, which appeared to be the precursors of the larger mushroom-shaped spines (Fig. $3 e, g$ ). The cisterns of SER and/or the dense plates of most mature spine apparatuses were found in close apposition to the side margins of the PSD (Fig. $4 a$ ) or just beneath the edge of the PSD (Fig. 4b). A thin projection of spine cytoplasm, called a spinule, often arises from the perforation in the PSD and invaginates the presynaptic axon (Figs. $3 d, 4 c$ ). A PSD was never found on the spinule. When 

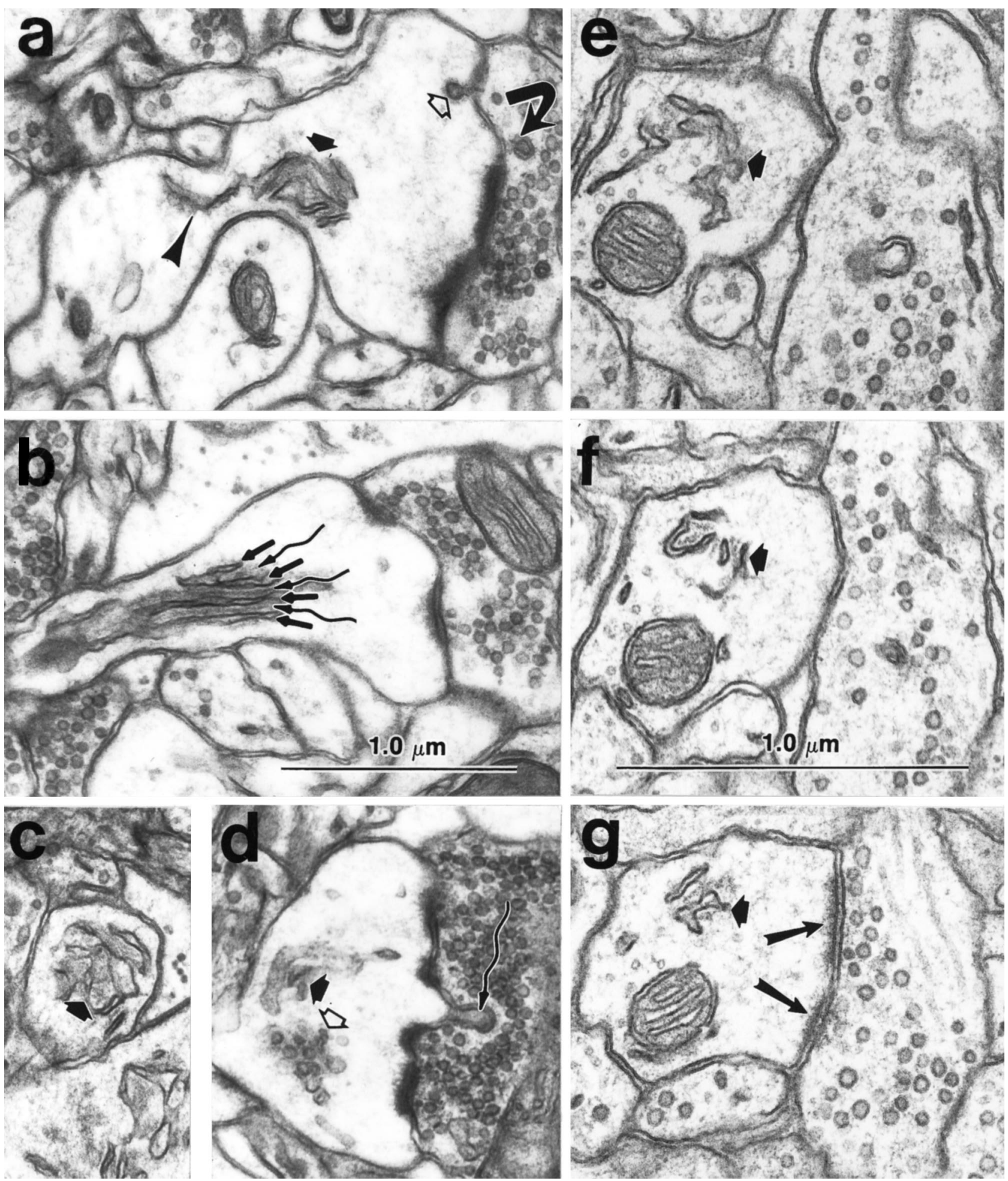

Figure 3. Mature dendritic spine apparatus. a, Spine apparatus (thick short arrow) elaborating from a single tubule of SER (arrowhead) in the dendritic shaft. A coated vesicle (open arrow) occurs at the membrane of the spine head, and a double-walled coated vesicle (curved arrow) occurs in the presynaptic bouton. See also Figure 5 for more discussion of this feature. $b$, Longitudinal section through a different spine apparatus clearly illustrating the lamination of SER (straight arrows) with dense staining plates (wavy arrows). $c$, Cross section of a spine apparatus (thick arrow) in a spine neck. $d$, Cluster of smooth vesicles (open arrow) in the head of a mushroom-shaped spine. This spine also contains a spine apparatus (thick filled arrow) and a spinule (wavy arrow) projecting toward the presynaptic bouton. A coated vesicle occurs in the presynaptic axon at the tip of the spinule (wavy arrow). $e-g$, Alternate serial sections through a spine apparatus (thick arrow) at the base of an emergent stubby dendritic spine that has a perforated PSD (two long arrows in $g$ illustrate two portions of the PSD). In the dendritic shaft, microtubules surround the cross-sectioned mitochondrion clearly delimiting the cytoplasm of the shaft from the emerging spine, which has no microtubules, but instead contains only a web of filamentous material. Scale bars: $a-g$ (shown in $b$ and $f$ ), $1.0 \mu \mathrm{m}$. 

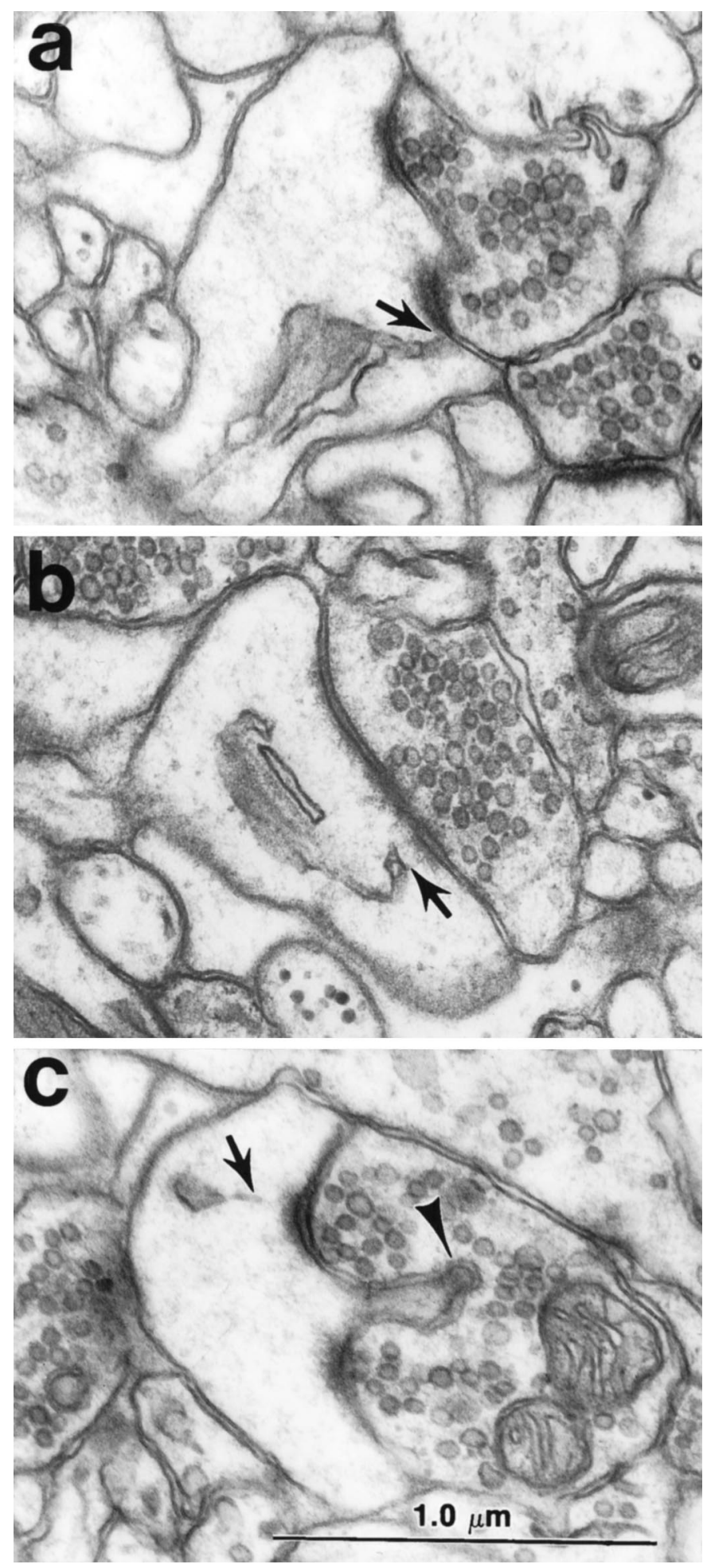

Figure 4. Association of spine apparatus with the PSD. $a, b$, A tubule of SER from the spine apparatus is directed to the outer edge of the PSD (arrows).c, The spine apparatus was never seen to be directed toward the spinule separating the two portions of the PSD. The presynaptic axon contains a coated vesicle at the tip of the spinule (arrow). Scale bar (shown in $c): 1.0 \mu \mathrm{m}$

24 spinules were observed through serial sections (20 on adult mushroom spines and 4 on day 15 mushroom spines), no SER was ever observed immediately beneath or within the spinule (Fig. 4c).
Although mitochondria were extremely rare in CA1 dendritic spines, the two we did see were in large spines that were not part of the unbiased sample discussed below and in both cases, the SER was closely associated with the mitochondrion as is typically seen in the dendritic shafts (see also Spacek and Lieberman, 1980).

\section{Evidence for endocytosis and exocytosis in dendritic spines}

Coated vesicles, double-walled vesicles, smooth vesicles, and multivesicular bodies (MVBs) are all part of the endosomal system that is involved in membrane cycling in neurons and other cells. Clathrin-coated pits occur at the plasma membrane and indicate a site where endocytosis begins. Both coated vesicles and coated pits were found in the dendritic spines and their presynaptic boutons. The coated vesicles or pits were found in all spine types, adjacent to the PSDs (e.g., Fig. 3a, open arrow) or at the side opposite from the PSD budding into the dendritic spine heads (Fig. $5 a$ ). Coated vesicles or pits were also found budding from the plasma membrane of the presynaptic axon across from the tips of spinules (Figs. 3d, 4c). In addition to the typical spinules found in the perforations of PSDs located on mushroom-shaped dendritic spines, a reciprocal spinule was observed emerging from the presynaptic bouton into the spine at the tip of which was a coated vesicle into the spine. The frequent occurrence of coated vesicles on the spinules is consistent with the hypothesis that spinules are also involved in the processes of endocytosis and exocytosis. Surprisingly, spinules were found on the heads of many thin spines next to the macular PSD either projecting into the presynaptic bouton or into an adjacent astrocytic process.

Double-walled vesicles occur when endocytosis involves the incorporation of the plasma membrane from an adjacent process into the vesicle created by the plasma membrane of the engulfing process. Double-walled vesicles were observed both presynaptically (Fig. 3a, curved arrow) and along the necks of dendritic spines (see Harris and Stevens, 1989, their Figs. 2e, 3e).

MVBs are considered to be secondary lysosomes involved in digesting intracellular organelles or fused single- or double-walled vesicles (Alberts et al., 1983). MVBs occurred in some of the adult mushroom-shaped spines, where they appeared in close association with the spine apparatus (Fig. 5b). MVBs were also occasionally found in continuity with tubules of SER in the dendritic shaft at the bases of spines.

Smooth vesicles could result from pinocytosis, uncoating of endocytic vesicles, or budding from the SER. Smooth vesicles occurred in the cytoplasm of the spine head (Figs. 1b, 2a,b, 3d), adjacent to the spine plasma membrane (Fig. $5 c$ ), and fusing with the plasma membrane (Fig. $5 d$ ). Together, these observations provide strong evidence for considerable endocytotic and exocytotic activity in dendritic spines.

\section{Quantification of different types of SER in unbiased samples of dendritic spines from area CA1}

A total of 203 dendritic spines were analyzed through serial sections (Table 1; see also Harris et al., 1989, 1992, for a description of the unbiased series sample method that was used previously to compare spine numbers by type across these two ages). Thin, mushroom, and stubby spines occurred in approximately equal proportions in the day 15 sample, whereas thin spines predominated in the adult sample. The proportion of mushroomshaped spines was similar at both ages, but the stubby spines were more frequent in the day 15 sample than in the adult sample. Five 

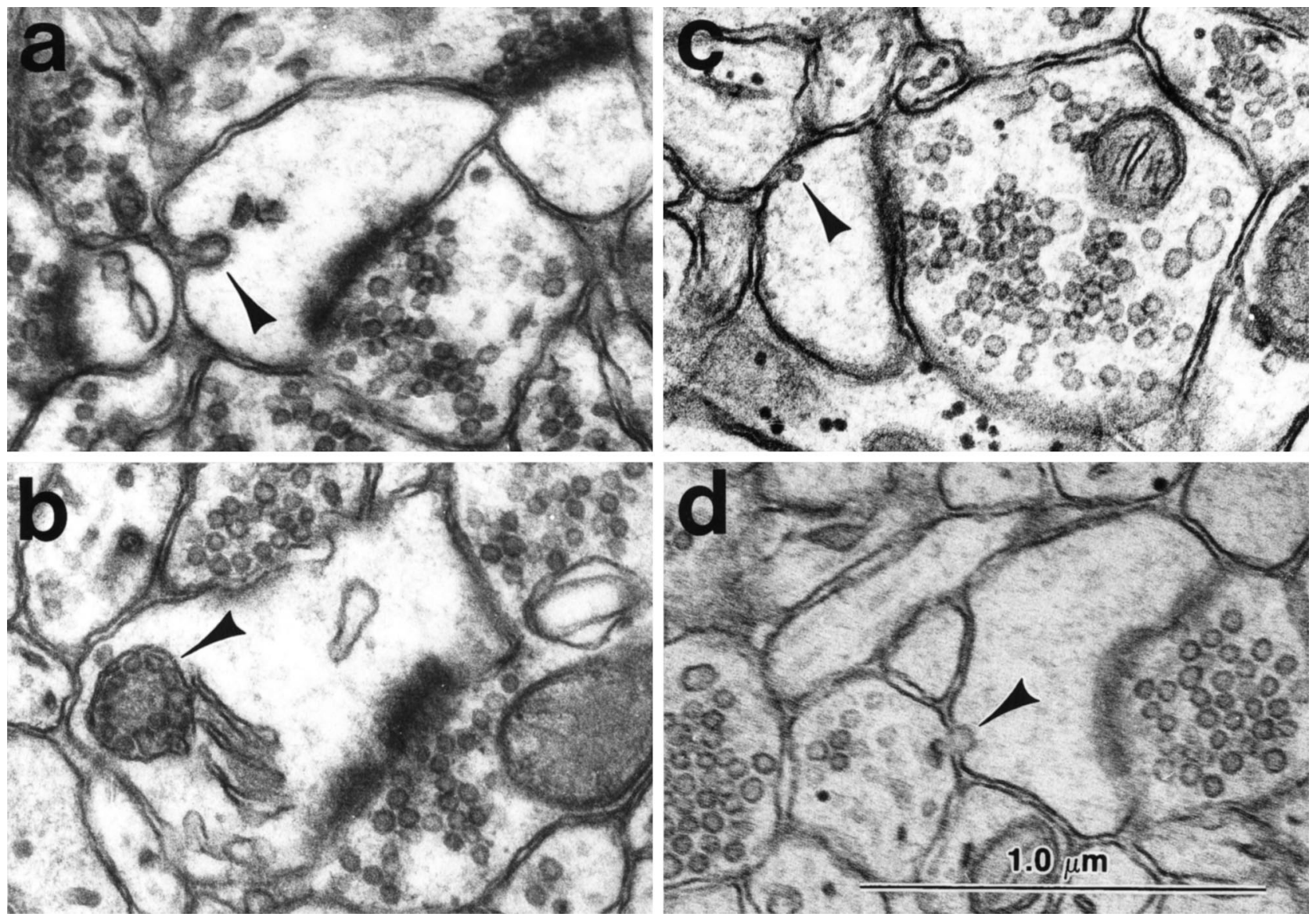

Figure 5. Ultrastructural evidence for local endocytosis and exocytosis in the spine heads. $a$, Coated vesicle invaginating the plasma membrane of a spine head located away from the vicinity of the PSD. $b$, Membrane delimited MVB associated with the spine apparatus in the spine head. $c$, Smooth vesicle in the spine head adjacent to the plasma membrane. $d$, Smooth vesicle fusing with the plasma membrane of the spine head. (This image is somewhat soft because of enlargement from the side of a negative that was part of a longer series.) Scale bar (shown in $d$ ): $1.0 \mu \mathrm{m}$.

branched spines occurred in the adult, but none occurred in the day 15 sample. At both ages, most of the spines had a macular PSD. In the day 15 sample, 13 of the spines in the mushroom and stubby categories had a perforated PSD; 4 of these PSDs had spinules in the perforations. In the adult sample, 22 of the spines, mostly in the mushroom category, had perforated PSDs, and 10 of these also had spinules. All heads of the five branched spines in the adult sample had macular PSDs.

The SER could be categorized according to varying degrees of complexity as forming one or more smooth vesicles, one or more tubules, or a fully elaborated spine apparatus. At day $15,58 \%$ of all dendritic spines contained at least one smooth vesicle or tubule of SER, and in the adult, $48 \%$ of all spines contained some type of SER (Fig. 6a). SER was found in 50\% of the day 15 thin spines but in only $24 \%$ of the adult thin spines. SER was found in $77 \%$ of the day 15 mushroom spines and $93 \%$ of the adult mushroom spines. At day 15, $51 \%$ of the stubby spines had SER, whereas only one of the four stubby spines in the adult sample contained SER.

In the day 15 sample, $28 \%$ of the spines contained one or more smooth vesicles and $29 \%$ contained at least one tubule of SER. In the mushroom and stubby categories, some spines had more than one tubule, and occasionally ( $2 \%)$, a large stubby spine contained a spine apparatus (Fig. 6b).

In the adult sample, $15 \%$ of the thin spines contained one or more smooth vesicles, and $\sim 9 \%$ contained a tubule of SER that connected to the shaft SER (Fig. $6 c$ ). Of the 28 adult mushroomshaped spines, $82 \%$ contained a mature spine apparatus; all but 2 of these had perforated PSDs. Most of the mature mushroomshaped spines had a spine apparatus that traversed both the head and the neck (57.1\%), although $11 \%$ had the spine apparatus in

Table 1. Number of synapses analyzed in each category at each age

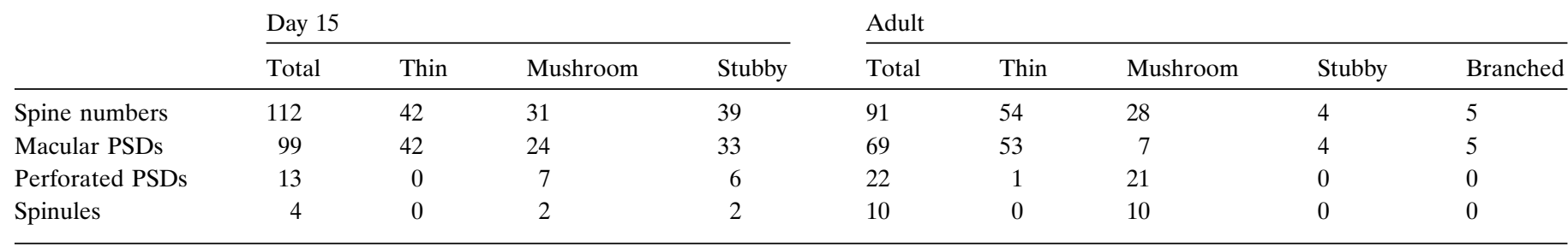


a)

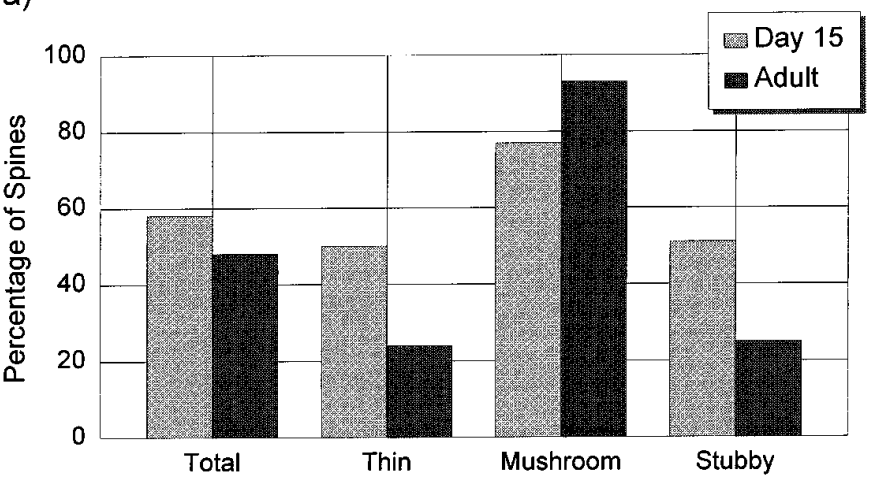

b) Day 15

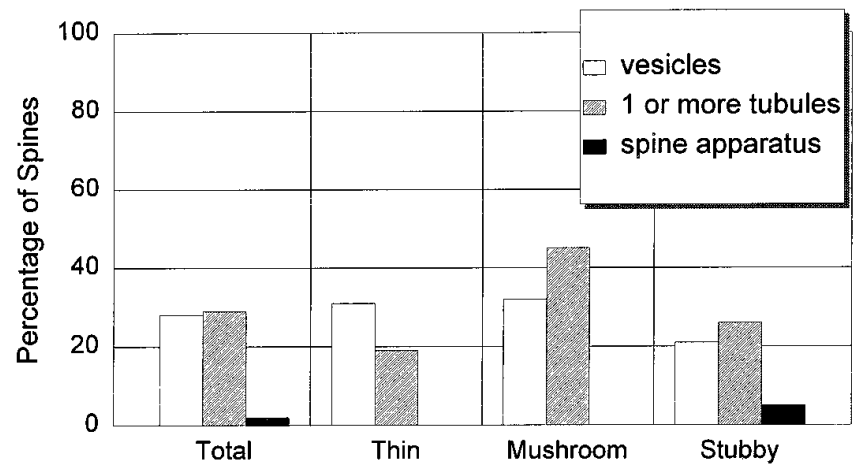

c) Adult

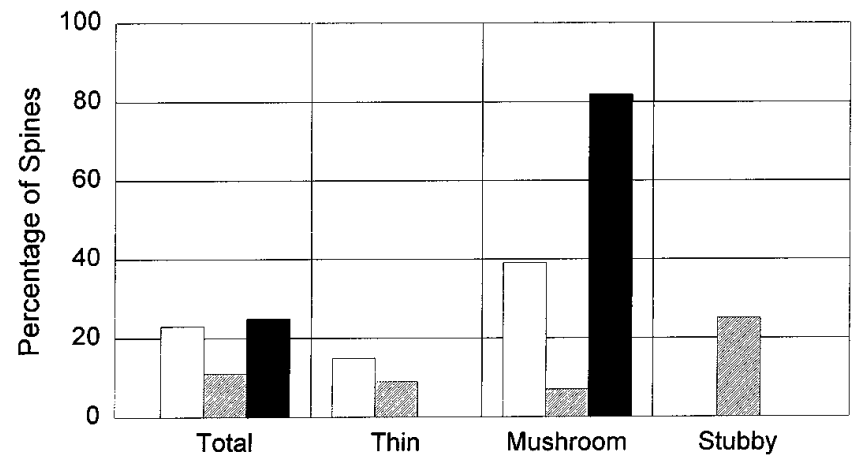

Figure 6. Quantification of dendritic spines containing smooth vesicles, tubules of SER, and/or a spine apparatus. $a$, Percentage of dendritic spines containing SER in any form at both ages. $b$, Different forms of SER in dendritic spines at day 15. $c$, Different forms of SER in the adult spines. (There was a numerical error for the SER in thin spines in Harris and Spacek, 1995; the data in these graphs are correct.)

the spine head only, and $14 \%$ had the spine apparatus in the spine neck only. Approximately $39 \%$ of the adult mushroom spines also had smooth vesicles, and $7 \%$ contained only one or more tubules of SER but no dense plates. The one adult stubby spine contained a single tubule of SER. Two of the adult branched spines contained smooth vesicles, two contained tubules of SER, and one did not have any SER in it (for simplicity these data are not graphed in Fig. 6).

It was obviously not possible to make statistical comparisons

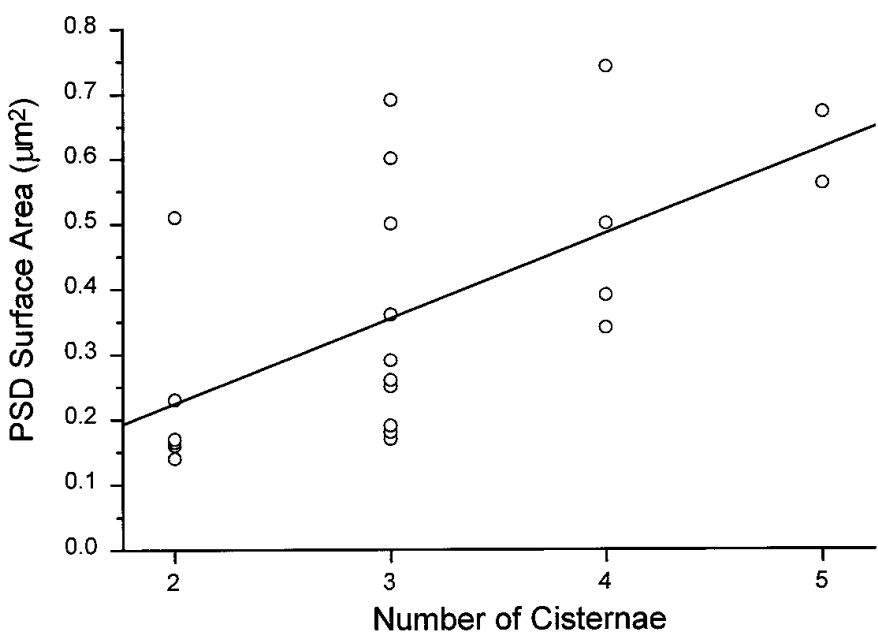

Figure 7. Correlation between total PSD surface area and the number of cisternae in the spine apparatus of mushroom-shaped dendritic spines in the adult hippocampus (CA1). Linear regression analysis: $r=0.6, \mathrm{SD}=$ $0.16, p<0.003, n=22$ different spines.

between the immature and mature samples, because, owing to the labor-intensive nature of this work, we limited the quantitative analyses to a single adult animal that had perfect tissue preservation. In this way, too, we could be sure that the differences between spine types in the adult were not a consequence of variations among animals, because all the spines came from a single rat. We have also examined serial sections from hippocampal area CA1 of two other mature rats, and qualitatively, a similar pattern occurred whereby spine apparatuses were observed in the larger spines that had perforated synapses, whereas many of the small thin spines had no SER.

\section{Larger PSDs are associated with larger and more complex spine apparatuses}

The number of cisterns of the spine apparatus increased with the total reconstructed area of the PSD (Fig. 7). Most adult spine apparatuses had three cisterns and, as indicated above, $91 \%$ of the mushroom spines with spine apparatuses also had perforated PSDs. The highest number of cisterns we saw was eight, although the spine containing this apparatus was not part of the unbiased sample and, therefore, is not plotted in Figure 7.

\section{Three-dimensional measurement of spine SER and spine apparatus}

Three-dimensional reconstructions (Fig. 8) and volumetric measurements were obtained for representative dendritic spines and the SER or spine apparatus they contained (Table 2). At both ages, the cisterns and vesicles of SER occupied only $2-3.5 \%$ of the total spine volume. The volume of the dense plate material measured only $0.001 \mu \mathrm{m}^{3}$ in the adult mushroom-shaped spine (M1 in Table 2); however, because of the difficulty of tracing this component, it was not measured in the other spines. The convoluted membranes of the SER had total surface areas ranging from $0.12 \mu \mathrm{m}^{2}$ in the adult thin spine to $2.19 \mu \mathrm{m}^{2}$ for the largest spine apparatus in the adult mushroom-shaped spine (M3 in Table 2). This membrane area was substantial and ranged from 12 to $40 \%$ of the value found for the entire plasma membrane of the spines (Table 2).

The cross-sectional areas of SER profiles were measured in the spine necks where they averaged 7-9\% for the fully reconstructed spines (Table 2). The cross-sectional area of SER profiles were 


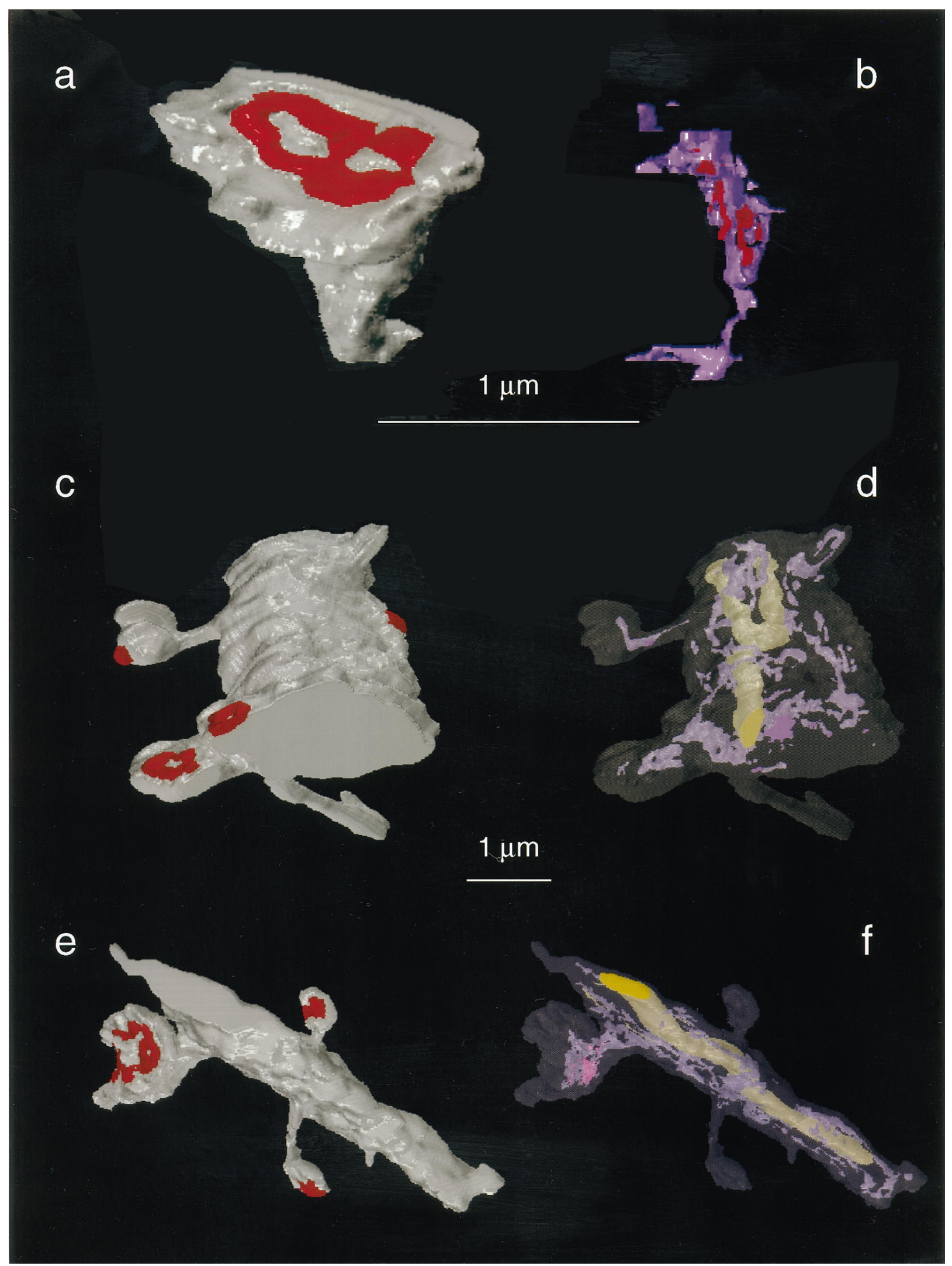

Figure 8. Three-dimensional reconstructions of dendritic spines, dendrites, and the SER they contained. $a$, An adult mushroom-shaped spine with a perforated PSD, which is adult spine M1 in Table 2. $b$, The reconstructed spine apparatus of the spine in $a$ is oriented to illustrate three forks of "purple" SER interdigitating with "red" dense plates. This spine apparatus originates from a thin tubule of SER near the base of the spine. The spine apparatus traverses the top half of the spine neck as well as part of the enlarged spine head. In addition, there are a couple of free smooth vesicles in the spine head. $c, d$, Day 15 dendritic segment where the top thin spine was graphically removed from the dendrite to obtain the quantitative values for the day 15 spine T in Table 2 . Figure legend continues. 


\begin{tabular}{|c|c|c|c|c|c|c|c|}
\hline $\begin{array}{l}\text { Age and } \\
\text { spine shape }\end{array}$ & $\begin{array}{l}\text { PSD } \\
\text { area } \\
\left(\mu \mathrm{m}^{2}\right)\end{array}$ & $\begin{array}{l}\text { Spine } \\
\text { volume } \\
\left(\mu \mathrm{m}^{3}\right)\end{array}$ & $\begin{array}{l}\text { SER or SA } \\
\text { volume } \\
\left(\mu \mathrm{m}^{3}\right)\end{array}$ & $\begin{array}{l}\% \\
\text { Spine } \\
\text { volume }\end{array}$ & $\begin{array}{l}\text { Spine } \\
\text { membrane } \\
\text { area }\left(\mu \mathrm{m}^{2}\right)\end{array}$ & $\begin{array}{l}\text { SER or SA } \\
\text { membrane } \\
\text { area }\left(\mu \mathrm{m}^{2}\right)\end{array}$ & $\begin{array}{l}\% \text { Spine } \\
\text { membrane } \\
\text { area }\end{array}$ \\
\hline \multicolumn{8}{|l|}{ Day 15} \\
\hline $\mathrm{T}$ & 0.05 & 0.10 & 0.0032 & 3.2 & 0.98 & 0.22 & 23 \\
\hline $\mathrm{S}$ & 0.19 & 0.24 & 0.0083 & 3.5 & 1.95 & 0.38 & 20 \\
\hline $\mathrm{T}$ & 0.13 & 0.06 & 0.0014 & 2.4 & 0.98 & 0.12 & 12 \\
\hline M1 & 0.25 & 0.25 & 0.0070 & 2.8 & 2.48 & 0.90 & 36 \\
\hline M2 & 0.50 & 0.38 & 0.0110 & 2.9 & 3.71 & 1.27 & 34 \\
\hline M3 & 0.79 & 0.64 & 0.0220 & 3.4 & 5.42 & 2.19 & 40 \\
\hline M1 neck & $\mathrm{n} / \mathrm{a}$ & 0.03 & 0.0028 & $8.6 \pm 5.2$ & 0.56 & 0.34 & 61 \\
\hline M2 neck & $\mathrm{n} / \mathrm{a}$ & 0.01 & 0.0008 & $7.0 \pm 4.7$ & 0.34 & 0.10 & 28 \\
\hline
\end{tabular}

At each age, the values are arranged down the table in the order of increasing PSD area. Some of these spines are visualized in Figure 8, as indicated in its legend.

also measured in the cross-sectioned necks of 15 additional mushroom-shaped spines and expressed as the percent of the neck profile area. In these spines, SER profiles occupied from $7 \%$, where a single thin tubule occurred, up to $21 \%$, where the cisterns of spine apparatus were located in the spine neck. When the intercisternal dense plates were also added to the cisterns of SER, the spine apparatus occupied up to $36 \%$ of the spine neck crosssectional area (e.g., see Fig. 3c).

\section{Relationship of the SER in the dendritic shafts to spines and synapses along their lengths}

Representative reconstructions were obtained from portions of day 15 and adult hippocampal dendritic segments. On visualization, it appeared that the amount of SER in the parent dendritic shaft was elevated in regions where dendritic spines originated from the shaft (e.g., Fig. 8d,f). To test this hypothesis, the SER was quantified by summing the areas of its profiles in each section of six dendritic segments from the adult hippocampus (Table 3, Fig. 9). Each dendritic segment was then divided into discrete segments with and without spines. Dendritic spines were found to cluster, ranging from one to eight spines per cluster with sections having no spine origins delimiting each cluster. The correlation between spine number and the cumulative amount of SER in the dendritic shaft beneath each cluster or delimiting region was determined using Lotus 1,2,3 software. For example, in Table 3, dendrite 1 (D1) was $0.5 \mu \mathrm{m}$ in diameter and had 14 thin spines, 3 mushroom spines, and 1 shaft synapse along its length of $3.1 \mu \mathrm{m}$ (42 serial sections, each $0.073 \mu \mathrm{m}$ thick). On average, $8.2 \pm 3.5 \%$ of the area of each cross-sectioned profile of D1 was filled with SER. Dendrite 1 had 12 discrete spine clusters and delimiting regions, and the amount of SER in the dendritic shaft correlated with the number of spines in the cluster or 0 spines in the delimiting region $(r=0.87, p<0.0005)$ (Table 3, Fig. $9 a)$. For five of the six dendritic segments, the correlations were high and reached statistical significance (Table 3 ). The distribution of the percentage of the dendritic shaft occupied by the SER paralleled the areal measurements of the SER in each section, because the dendritic segments were of relatively uniform diameter along their lengths. In fact, Figure $9 b$ illustrates dendrite 6 , which was twice as wide as dendrite 1 , yet the amount of SER in dendrite 6 was less. Nevertheless, the correlation between the nonuniform distribution of SER and number of spine/synapse origins along the length of dendrite 6 was just as good $(0.94, p<0.001)$ as for dendrite 1 . These observations suggest that the nonuniform distribution of the SER in the dendritic shaft is influenced by synaptic activity originating at the spine heads.

\section{DISCUSSION}

The dimensions of the SER and spine apparatuses were proportional to overall spine and synapse size. The highly convoluted membranes of the SER tubules both in the spine and in the parent dendrite provide significant area for modifying spine and synaptic structure (Jones and Harris, 1995), for elevating and regulating calcium in spine heads and dendrites, for preventing calciuminduced excitotoxicity in the dendrites (Harris and Kater, 1994; Segal, 1995a), and for initiating a calcium signal that might ultimately regulate gene expression at the nucleus (Rosen et al., 1995).

\section{Evidence that spine apparatuses are associated primarily with perforated PSDs}

As in other brain regions, the spine apparatus in hippocampal area CA1 appeared in large dendritic spines that possessed perforated PSDs and was absent in small spines with macular PSDs (Gray, 1959; Jones and Powell, 1969; Peters and KaisermanAbramof, 1970; Spacek and Hartmann, 1983; Spacek, 1985; Harris and Stevens, 1989; Harris et al., 1992). This association was also valid in branching spines of the hippocampal CA3 region (Chicurel and Harris, 1992) and in the thalamic nuclei (Spacek and Lieberman, 1974). The SER and/or dense plates of the spine apparatus occurred in close apposition to the margins of the PSD and, thus, may serve to expand its surface during synaptic plastic-

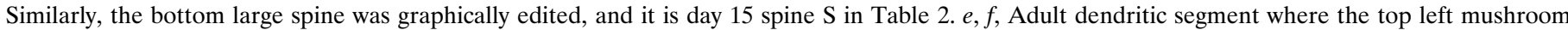

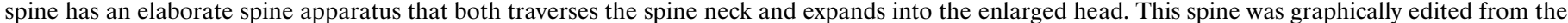

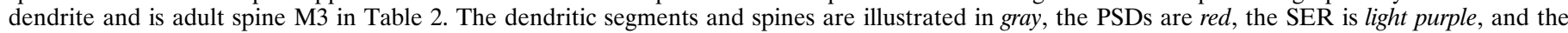

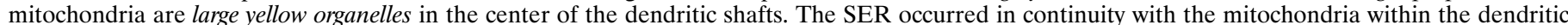
shafts. Scale bars: $a, b, 1 \mu \mathrm{m} ; c-f, 1 \mu \mathrm{m}$ (between the reconstructed dendrites). 


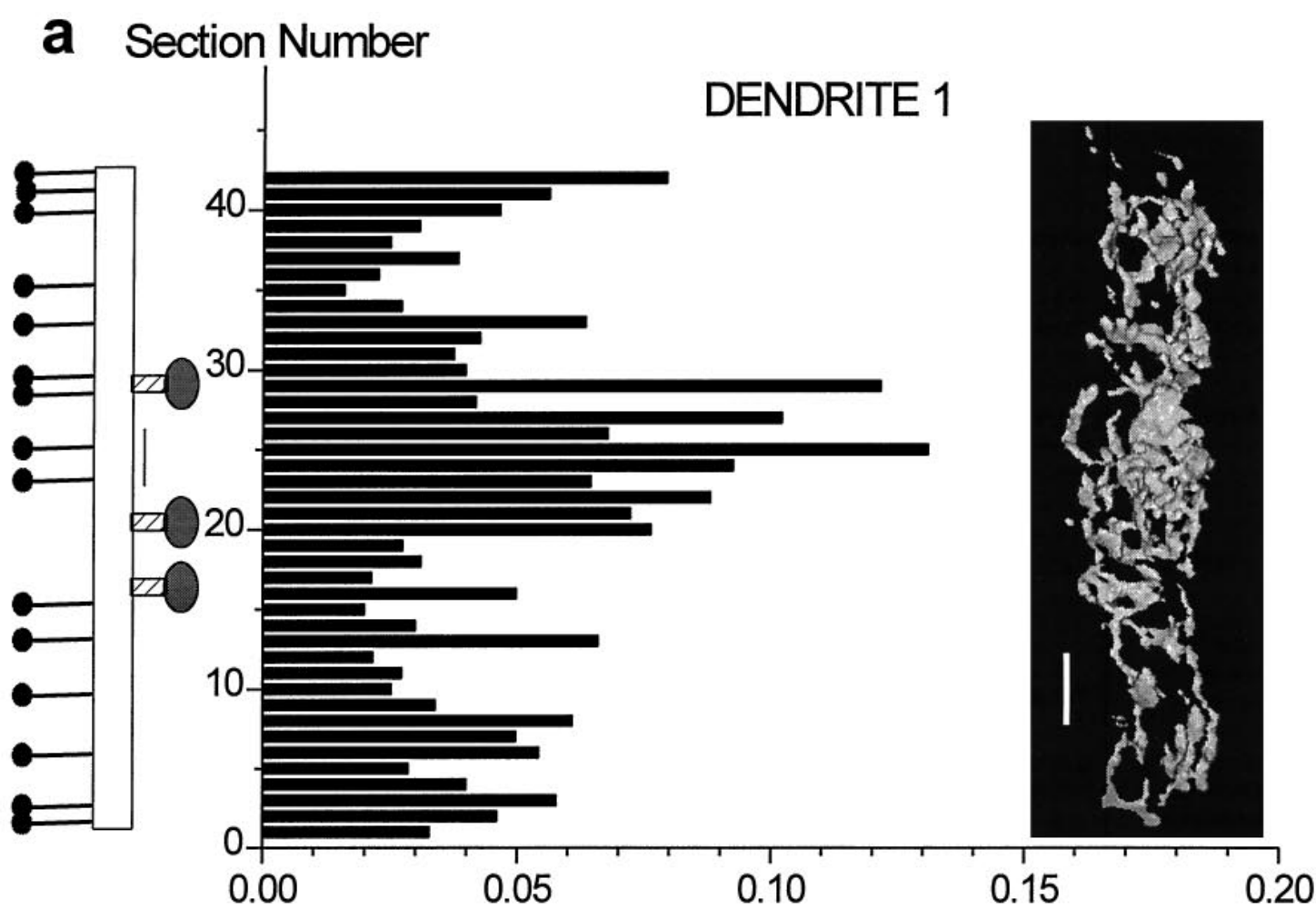

b

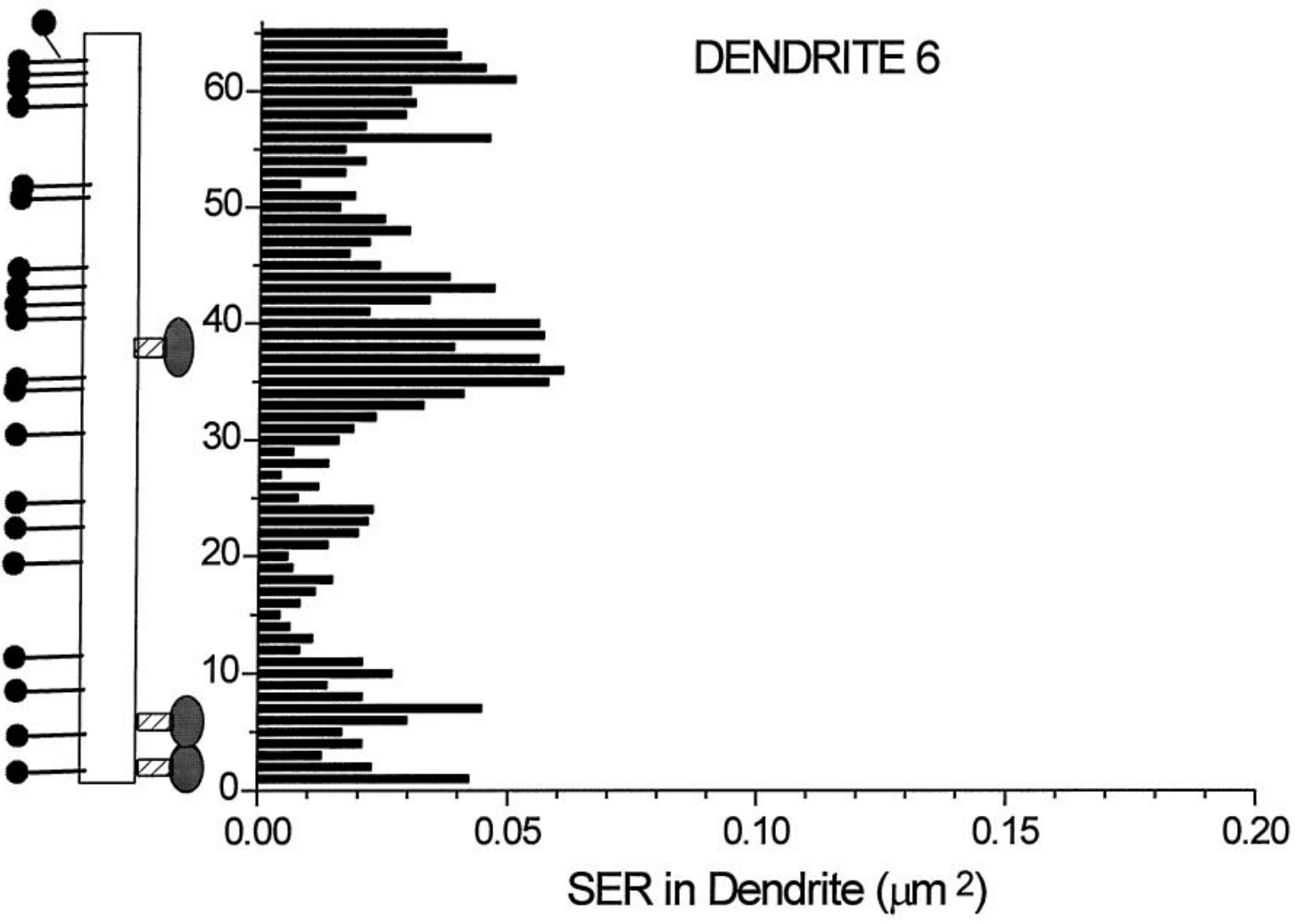

Figure 9. Relationship of SER cross-sectional areas to the distribution of dendritic spines and synapses along $(a)$ dendrite 1 and $(b)$ dendrite 6 from Table 3 . The $y$-axes are the section number, and the thickness of each bar is adjusted to match the relative difference in section thickness. The $x$-axes are the summed cross-sectional areas of SER in each section of dendritic shaft. The three-dimensional reconstruction of SER in dendrite 1 also shows the nonuniform distribution along the dendritic shaft. Figure legend continues. 
Table 3. Correlation between SER in segments of reconstructed dendritic shafts and the number of spine or synapse origins occurring in discrete locations along their lengths

\begin{tabular}{|c|c|c|c|c|c|c|}
\hline Dendrite & $\begin{array}{l}\text { Segment } \\
\text { diameter } \\
(\mu \mathrm{m})\end{array}$ & $\begin{array}{l}\text { Segment } \\
\text { length } \\
(\mu \mathrm{m})\end{array}$ & $\begin{array}{l}\text { Types of spines } \\
\text { or synapses } \\
\text { (no.) }\end{array}$ & $\begin{array}{l}\% \text { Dendritic } \\
\text { shaft filled } \\
\text { with SER } \\
(\text { mean } \pm \mathrm{SD})\end{array}$ & $\begin{array}{l}\text { Spine clusters } \\
\text { and delimiting } \\
\text { regions } \\
\text { (no.) }\end{array}$ & $\begin{array}{l}\text { Correlation }(r) \text { between } \\
\text { shaft SER and spine } \\
\text { or synapse number in } \\
\text { a cluster }\end{array}$ \\
\hline D1 & 0.5 & 3.1 & $14 \mathrm{~T}, 3 \mathrm{M}, 1 \mathrm{Sh}$ & $8.2 \pm 3.5$ & 12 & $0.87, p<0.0005$ \\
\hline D2 & 0.5 & 3.2 & $11 \mathrm{~T}, 2 \mathrm{M}$ & $5.2 \pm 2.6$ & 12 & $0.68, p<0.01$ \\
\hline D3 & 0.5 & 1.5 & $5 \mathrm{~T}, 1 \mathrm{Br}$ & $2.4 \pm 1.2$ & 4 & $0.93, p<0.05$ \\
\hline D4 & 0.5 & 3 & $14 \mathrm{~T}, 1 \mathrm{M}, 1 \mathrm{Br}$ & $5.1 \pm 2.1$ & 18 & $0.38, p=0.06$ \\
\hline D5 & 0.5 & 3.1 & $9 \mathrm{~T}, 1 \mathrm{~S}, 1 \mathrm{Sh}$ & $6.6 \pm 3.8$ & 10 & $0.92, p<0.0005$ \\
\hline D6 & 1 & 3.6 & $20 \mathrm{~T}, 3 \mathrm{M}$ & $4.4 \pm 2.5$ & 14 & $0.94, p<0.001$ \\
\hline
\end{tabular}

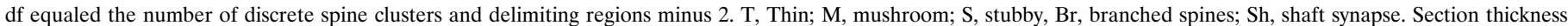
for D1 $=0.073 \mu \mathrm{m}$, and section thickness for D2-D6 $=0.055 \mu \mathrm{m}$.

ity (Jones and Harris, 1995). When a spine apparatus occurred in a CA1 dendritic shaft, the emerging stubby spine found near to it had a perforated PSD. In some brain regions, dendritic spines contain a reticular network of SER but no spine apparatus [e.g., Purkinje spiny branchlets (Harris and Stevens, 1988; Martone et al., 1993)]. All of these Purkinje spines had macular PSDs (Harris and Stevens, 1988), which supports the hypothesis that spine apparatuses are not associated with nonperforated PSDS.

Whereas the association between perforated PSDs and spine apparatuses seems to be obligatory (or nearly so) in adult hippocampus and neocortex (Spacek and Hartmann, 1983), this relationship may not hold for all sites on the neuron nor during development. For example, a "cisternal organelle," which is morphologically identical to the spine apparatus, occurs in the axonal hillock of cortical pyramidal neurons beneath axo-axonic synapses that have symmetrically thin presynaptic and postsynaptic densities that are not perforated (Peters et al., 1991; Benedeczky et al., 1994). Conversely, perforated PSDs on dendritic shafts of hippocampal dentate granule cells had no spine apparatuses (Geinisman et al., 1987). During development in both hippocampal area CA1 and neocortex, the perforated PSDs were usually not associated with spine apparatuses (Westrum et al., 1980; Harris et al., 1989, 1992; Itarat and Jones, 1992). These results suggest that perforated PSDs can form before the spine apparatus, but once the spine emerges from the dendrite, the apparatus goes with it or is elaborated within the spine head.

\section{Involvement of the SER and spine apparatus in endocytosis and exocytosis and synaptic remodeling}

Endocytic activity was demonstrated in spines by the presence of coated vesicles, double-walled vesicles, and MVBs. Synaptic spinules (Westrum and Blackstad, 1962; Tarrant and Routtenberg, 1977) frequently had coated vesicles on their tips and appeared to be involved in endocytosis on the presynaptic side. Exocytosis was suggested by smooth vesicles fusing with the plasma membrane, although these might have been pinocytotic. The first interpretation is favored, because it provides a postsynaptic mechanism for insertion of receptors and other transmembrane molecules in an activity-dependent manner (Alberts et al., 1983; Maletic-Savatic et al., 1995). Whether the small smooth vesicles also contain releasable signals in their lumen remains to be determined. In addition, the SER and/or dense plates of the spine apparatus, found in close apposition with the edge of the PSD, might also serve to expand the PSD during synaptic plasticity (Jones and Harris, 1995).

\section{Impact of the SER and spine apparatuses on the electrotonic properties of spine necks}

Theoretical considerations of dendritic spines have emphasized that one key to understanding their function is to determine the resistance of the spine neck. This resistance will depend on neck length, cross-sectional area, cytoplasmic resistivity, and internal organelles (Wickens, 1988). The SER in CA1 spines occupied $<4 \%$ of the spine volume. Mushroom spine necks had the most SER, with up to $36 \%$ of the cross-sectional area filled by a spine apparatus. Nevertheless, realistic models suggest that even this occupancy would have a small or transient impact on electrotonic charge transfer from the synapse to the parent dendrite (Wilson, 1984; Brown et al., 1988; Harris and Stevens, 1988; Wickens, 1988).

\section{Regulation of calcium in dendritic spines and parent dendrites}

Calcium can reach $20-40 \mu \mathrm{M}$ in CA1 spine heads during tetanic stimulation of their synapses (Petrozzino et al., 1995). After a single synaptic event, the calcium remained high in the CA1 spine heads for at least $100 \mathrm{msec}$ before shaft levels also became elevated above the baseline concentration of much less than $1 \mu \mathrm{M}$ calcium (Segal, 1995b; Svoboda et al., 1996). After repeated synaptic activation, calcium remained high in the spine heads for seconds (Petrozzino et al., 1995). These results show that calcium is compartmentalized in CA1 spine heads after synaptic activation. The peak calcium occurring in a particular spine head will be sensitive to spine dimensions, cytoplasmic buffering, and the modulation of calcium via release from the SER, via sequestration into the SER, or from extrusion, via the $\mathrm{Na}^{+} / \mathrm{Ca}^{2+}$ exchange on the plasma membrane (Holmes and Levy, 1990; Zador et al., 1990; Gold and Bear, 1994; Woolf and Greer, 1994).

The volume percentage of SER in spines ranged from 2 to $4 \%$, which is consistent with other cell types in which the SER is also 
thought to regulate calcium (Alberts et al., 1983; Bundgaard, 1991). Several approaches have found calcium or its precipitates to be high in SER and spine apparatuses (Burgoyne et al., 1983; Fifkova et al., 1983; Andrews and Reese, 1990; Buchs et al., 1994). Receptors for $\mathrm{IP}_{3}$ have been located along the SER membranes in cerebellar dendrites and spines (Mignery et al., 1989; Villa et al., 1992), and ryanodine receptors occurred on SER in the dendrites only (Ellisman et al., 1990). Activation of these receptors leads to release of calcium from intracellular stores. The SER membranes in cortical dendritic spines have calcium ATPases, which mediate reuptake of calcium (Cohen and Kriho, 1991), and cerebellar spine SER contains calsequestrin, a low-affinity, high-capacity calcium buffer (Takei et al., 1992). Similarly, the large CA1 spines could release and sequester calcium via their intracellular stores of SER.

Only $24 \%$ of the adult thin spines contained any form of SER, suggesting that calcium is regulated by some mechanism not involving the SER. A candidate mechanism is cytoplasmic buffers, such as calbindin (Ellisman et al., 1990). If calcium buffers are affective in small hippocampal spine heads, then free calcium is unlikely to diffuse $>\sim 0.1 \mu \mathrm{m}$ (Allbritton et al., 1992). Because thin spines are usually $>0.5 \mu \mathrm{m}$ long, it is unlikely that synaptic calcium will leave the thin spine heads.

Local elevation of calcium at one point on a cell can result in a propagating wave of calcium throughout the cell (Cornell-Bell et al., 1990; Clapham, 1995). The site where calcium is first elevated has been called the elementary point source (Bootman and Berridge, 1995). In neurons, it will be important to identify whether elementary point sources of calcium are found in the dendrites, because calcium is required to initiate gene expression in response to synaptic activity (Rosen et al., 1995; Finkbeiner and Greenberg, 1996). It seems likely that calcium released from intracellular stores will be needed to overcome the cytoplasmic buffering. Calcium entry during synaptic activation on spine heads might initiate release of calcium from the SER if $\mathrm{IP}_{3}$ is also generated via activation of G-proteins, such as those associated with the metabotropic glutamate receptors (Baude et al., 1993; Nusser et al., 1994). Because $\mathrm{IP}_{3}$ can diffuse up to $24 \mu \mathrm{m}$ (Allbritton et al., 1992), it could readily activate release of calcium stores either in the spine head or from the SER in the parent dendritic shafts. We suggest that the large hippocampal spines are the best candidates to be sources of calcium, because they contain large stores of intraspine SER.

When calcium reaches moderately high concentrations, which should be easy to achieve in the limited volume of even a relatively large spine head $\left(<0.2 \mu \mathrm{m}^{3}\right)$ (Harris and Stevens, 1989), second messenger systems principally involving protein kinases lead to the phosphorylation of specific proteins (Rosen et al. 1995). The local effect can be a modification of synaptic strength, for example, by changing the properties of specific glutamatergic receptors (Kennedy, 1989). Structural changes in the spine could also occur rapidly, because the spines contain an abundance of actin (Fifkova and Morales, 1989; Morales and Fifkova, 1989). At higher concentrations, reuptake into SER or extrusion via the plasma membrane would return calcium to its normally low levels in the spine cytoplasm, thus ending the synaptic event. This exquisite control of calcium in dendritic spines can protect the dendrites from high calcium, which could detubulate microtubules and devastate dendritic structure (Harris and Kater, 1994; Segal, 1995a) while facilitating the moderate elevation in calcium needed during normal synaptic transmission and plasticity.

If the calcium released from the SER in the spine head could initiate release of calcium in the dendritic SER, then a calcium signal might ultimately spread to the nucleus via the SER, which is known to be contiguous with the nucleus. In this way, the elevation of calcium during synaptic potentiation might be sufficient to alter gene expression of the neuron, even though free calcium is unlikely to diffuse $>0.1 \mu \mathrm{m}$ (Allbritton et al., 1992; Rosen et al., 1995; also see Deisseroth et al., 1996).

\section{Concluding remarks}

These measurements of the SER and the spine apparatus show how well suited they are to modulate the intracellular milieu of hippocampal dendritic spines and their synapses. The continuity between SER in the spines and SER of the dendrites provides a simple mechanism whereby a calcium signal generated at the synapse could induce new gene expression at the soma, hundreds of microns away. Future work should determine whether large spines are elementary point sources of synaptic calcium, whether these organelles are affected by synaptic plasticity, and whether the composition of synapses and SER or spine apparatuses is similar, to determine their role in the structural modification of spines and synapses. Continued efforts along these lines will be important for understanding how each component of the dendritic spine modulates synaptic function.

\section{REFERENCES}

Alberts B, Bray D, Lewis J, Raff M, Roberts K, Watson JD (1983) Molecular biology of the cell. New York: Garland.

Allbritton NL, Meyer T, Stryer L (1992) Range of messenger action of calcium ion and inositol 1,4,5-trisphosphate. Science 258:1812-1815.

Andrews SB, Reese TS (1990) Intracellular structure and elemental analysis in rapid-frozen neurons. Ann NY Acad Sci 483:284-294.

Baude A, Nusser Z, Roberts JD, Mulvihill E, McIlhinney RA, Somogyi P (1993) The metabotropic glutamate receptor (mGluR1 alpha) is concentrated at perisynaptic membrane of neuronal subpopulations as detected by immunogold reaction. Neuron 11:771-787.

Benedeczky I, Molnar E, Somogyi P (1994) The cisternal organelle as a $\mathrm{Ca}^{2+}$-storing compartment associated with GABAergic synapses in the axon initial segment of hippocampal pyramidal neurones. Exp Brain Res 101:216-230.

Bootman MD, Berridge MJ (1995) The elemental principles of calcium signaling. Cell 83:675-678.

Broadwell RD, Cataldo AM (1983) The neuronal endoplasmic reticulum: its cytochemistry and contribution to the endomembrane system. I. Cell bodies and dendrites. J Histochem Cytochem 31:1077-1088.

Broadwell RD, Cataldo AM (1984) The neuronal endoplasmic reticulum: its cytochemistry and contribution to the endomembrane system. II. Axons and terminals. J Comp Neurol 230:231-248.

Brown TH, Chang VC, Ganong AH, Keenan CL, Kelso SR (1988) Biophysical properties of dendrites and spines that may control the induction and expression of long-term synaptic potentiation. Neurol Neurobiol 35:201-264.

Buchs P-A, Stoppini L, Parducz A, Siklos L, Muller D (1994) A new cytochemical method for the ultrastructural localization of calcium in the central nervous system. J Neurosci Methods 54:83-93.

Bundgaard M (1991) The three-dimensional organization of smooth endoplasmic reticulum in capillary endothelia: its possible role in regulation of free cytosolic calcium. J Struct Biol 107:76-85.

Burgoyne RD, Gray EG, Barron J (1983) Cytochemical localization of calcium in the dendritic spine apparatus of the cerebral cortex and at synaptic sites in the cerebellar cortex. J Anat 136:634-635.

Chicurel ME, Harris KM (1992) Three-dimensional analysis of the structure and composition of CA3 branched dendritic spines and their synaptic relationships with mossy fiber boutons in the rat hippocampus. J Comp Neurol 325:169-182.

Choi DW (1995) Calcium: still center-stage in hypoxic-ischemic neuronal death. Trends Neurosci [Review] 18:58-60.

Clapham DE (1995) Calcium Signaling. Cell 80:259-268.

Cohen RS, Kriho V (1991) Localization of ATPase activity in dendritic spines of the cerebral cortex. J Neurocytol 20:703-715. 
Cornell-Bell AH, Finkbeiner SM, Cooper MS, Smith SJ (1990) Glutamate induces calcium waves in cultured astrocytes: long-range glial signaling. Science 247:470-473.

Deisseroth K, Bito H, Tsien RW (1996) Signaling from synapse to nucleus: postsynaptic CREB phosphorylation during multiple forms of hippocampal synaptic plasticity. Neuron 16:89-101.

Ellisman MH, Deerinck TJ, Ouyang Y, Beck CF, Tanksley SJ, Walton PD, Airey JA, Sutko JL (1990) Identification and localization of ryanodine binding proteins in the avian central nervous system. Neuron 5:135-146.

Fifkova E, Morales M (1989) Calcium-regulated contractile and cytoskeletal proteins in dendritic spines may control synaptic plasticity. Ann NY Acad Sci 568:131-137.

Fifkova E, Markham JA, Delay RJ (1983) Calcium in the spine apparatus of dendritic spines in the dentate molecular layer. Brain Res 266:163-168.

Finkbeiner SM, Greenberg ME (1996) $\mathrm{Ca}^{2+}$-dependent routes to ras: mechanisms for neuronal survival, differentiation, and plasticity? Neuron 16:233-236.

Geinisman Y, Morrell F, de Toledo Morrell L (1987) Synapses on dendritic shafts exhibit a perforated postsynaptic density. Brain Res 422:352-356.

Ghadially FN (1982) Ultrastructural pathology of the cell. London: Butterworths.

Gold JI, Bear MF (1994) A model of dendritic spine $\mathrm{Ca}^{+2}$ concentration exploring possible bases for a sliding synaptic modification threshold. Proc Natl Acad Sci USA 91:3941-3945.

Gray EG (1959) Axo-somatic and axo-dendritic synapses of the cerebral cortex: an electron microscopic study. J Anat 93:420-433.

Guthrie PB, Segal M, Kater SB (1991) Independent regulation of calcium revealed by imaging dendritic spines. Nature 354:76-80.

Harris KM (1994) Serial electron microscopy as an alternative or complement to confocal microscopy for the study of synapses and dendritic spines in the central nervous system. In: Three-dimensional confocal microscopy: volume investigation of biological specimens (Stevens JK, Mills LR, Trogadis JE, eds), pp 421-445. New York: Academic.

Harris KM, Kater SB (1994) Dendritic spines: cellular specializations imparting both stability and flexibility to synaptic function. Annu Rev Neurosci 17:341-371.

Harris KM, Spacek J (1995) Three-dimensional organization of SER and other organelles in dendritic spines of rat hippocampus (CA1). Soc Neurosci Abstr 21:594.

Harris KM, Stevens JK (1988) Dendritic spines of rat cerebellar Purkinje cells: serial electron microscopy with reference to their biophysical characteristics. J Neurosci 8:4455-4469.

Harris KM, Stevens JK (1989) Dendritic spines of CA1 pyramidal cells in the rat hippocampus: serial electron microscopy with reference to their biophysical characteristics. J Neurosci 9:2982-2997.

Harris KM, Jensen FE, Tsao B (1989) Ultrastructure, development, and plasticity of dendritic spine synapses in area CA1 of the rat hippocampus: extending our vision with serial electron microscopy and threedimensional analyses. Neurol Neurobiol 52:33-52.

Harris KM, Jensen FE, Tsao B (1992) Three-dimensional structure of dendritic spines and synapses in rat hippocampus (CA1) at postnatal day 15 and adult ages: implications for the maturation of synaptic physiology and long-term potentiation. J Neurosci 12:2685-2705.

Holmes WR, Levy WB (1990) Insights into associative long-term potentiation from computational models of NMDA receptor-mediated calcium influx and intracellular calcium concentration changes. J Neurophysiol 63:1148-1168.

Itarat W, Jones A (1992) Perforated synapses are present during synaptogenesis in rat neocortex. Synapse 11:279-286.

Jones DJ, Harris RJ (1995) An analysis of contemporary morphological concepts of synaptic remodelling in the CNS: perforated synapses revisited. Neurosci Rev 6:177-219.

Jones EG, Powell TPS (1969) Morphological variations in the dendritic spines of the neocortex. J Cell Sci 5:509-529.

Karnovsky MJ (1971) Use of ferrocyanide-reduced osmium tetroxide in electron microscopy. Proc 11th Annual Meeting of Cell Biology 146.

Kennedy MB (1989) Regulation of neuronal function by calcium. Trends Neurosci 12:417-420.

Krijnse-Locker J, Parton RG, Fuller SD, Griffiths G, Dotti CG (1995) The organization of the endoplasmic reticulum and the intermediate compartment in cultured rat hippocampal neurons. Mol Biol Cell 6:1315-1332.
Langford LA, Coggeshall RE (1980) The use of potassium ferricyanide in neural fixation. Anat Rec 197:297-303.

Lindsey JD, Ellisman MH (1985a) The neuronal endomembrane system. I. Direct links between rough endoplasmic reticulum and the cis element of the Golgi apparatus. J Neurosci 5:3111-3123.

Lindsey JD, Ellisman MH (1985b) The neuronal endomembrane system. II. The multiple forms of the Golgi apparatus cis element. J Neurosci 5:3124-3134.

Lindsey JD, Ellisman MH (1985c) The neuronal endomembrane system. III. The origins of the axoplasmic reticulum and discrete axonal cisternae at the axon hillock. J Neurosci 5:3135-3144.

Maletic-Savatic MM, Koothan T, Malinow R (1995) Dendritic calciumdependent exocytosis in cultured hippocampal neurons: role of calcium/ calmodulin protein kinase II. Soc Neurosci Abstr 21:1743.

Martone ME, Zhang Y, Simpliciano VM, Carragher BO, Ellisman MH (1993) Three-dimensional visualization of the smooth endoplasmic reticulum in Purkinje cell dendrites. J Neurosci 13:4636-4646.

Mignery GA, Sudhof TC, Takei K, DeCamilli P (1989) Putative receptor for inositol 1,4,5-trisphosphate similar to ryanodine receptor. Nature 342:192-195.

Morales M, Fifkova E (1989) Distribution of MAP 2 in dendritic spines and its colocalization with actin. An immunogold electron-microscope study. Cell Tissue Res 256:447-456.

Muller W, Connor JA (1991) Dendritic spines as individual neuronal compartments for synaptic Ca2+ responses. Nature 354:73-76.

Murphy TH, Baraban JM, Wier WG (1995) Mapping miniature synaptic currents to single synapses using calcium imaging reveals heterogeneity in postsynaptic output. Neuron 15:159-168.

Nusser Z, Mulvihill E, Streit P, Somogyi P (1994) Subsynaptic segregation of metabotropic and ionotropic glutamate receptors as revealed by immunogold localization. Neuroscience 61:421-427.

Peters A, Palay SL, Webster HD (1991) The fine structure of the nervous system: the neurons and supporting cells. Philadelphia: Saunders.

Peters A, Kaiserman-Abramof IR (1970) The small pyramidal neuron of the rat cerebral cortex. The perikaryon, dendrites and spines. J Anat 127:321-356.

Petrozzino JJ, Pozzo Miller LD, Connor JA (1995) Micromolar $\mathrm{Ca}^{2+}$ transients in dendritic spines of hippocampal pyramidal neurons in brain slice. Neuron 14:1223-1231.

Rosen LB, Ginty DD, Greenberg ME (1995) Calcium regulation of gene expression. In: Advances in second messenger and phosphoprotein research (Means AR, ed), pp 225-253. New York: Raven.

Segal M (1995a) Dendritic spines for neuroprotection: a hypothesis. [Review]. Trends Neurosci 18:468-471.

Segal M (1995b) Imaging of calcium variations in living dendritic spines of cultured rat hippocampal neurons. J Physiol (Lond) 486.2:283-295.

Spacek J (1985) Three-dimensional analysis of dendritic spines. II. Spine apparatus and other cytoplasmic components. Anat Embryol 171:235-243.

Spacek J (1994) Design CAD-3D: a useful tool for 3-dimensional reconstructions in biology [letter]. J Neurosci Methods 53:123-124.

Spacek J, Hartmann M (1983) Three-dimensional analysis of dendritic spines. I. Quantitative observations related to dendritic spine and synaptic morphology in cerebral and cerebellar cortices. Anat Embryol 167:289-310.

Spacek J, Lieberman AR (1974) Ultrastructure and three-dimensional organization of synaptic glomeruli in rat somatosensory thalamus. J Anat 117:487-516.

Spacek J, Lieberman AR (1980) Relationships between mitochondrial outer membranes and agranular reticulum in nervous tissue: ultrastructural observations and a new interpretation. $J$ Cell Sci 46:129-147.

Svoboda K, Tank DW, Denk W (1996) Direct measurement of coupling between dendritic spines and shafts. Science 272:716-719.

Takei K, Stukenbrok H, Metcalf A, Mignery GA, Sudhof TC, Volpe P, De Camilli P (1992) $\mathrm{Ca}^{2+}$ stores in Purkinje neurons: endoplasmic reticulum subcompartments demonstrated by the heterogeneous distribution of the $\mathrm{InsP}_{3}$ receptor, $\mathrm{Ca}^{2+}$-ATPase, and calsequestrin. J Neurosci 12:489-505.

Takei K, Mignery GA, Mugnaini E, Sudhof TC, De Camilli P (1994) Inositol 1,4,5-trisphosphate receptor causes formation of ER cisternal stacks in transfected fibroblasts and in cerebellar Purkinje cells. Neuron $12: 327-342$. 
Tarrant SB, Routtenberg A (1977) The synaptic spinule in the dendritic spine: electron microscopic study of the hippocampal dentate gyrus. Tissue Cell 9:461-473.

Villa A, Meldolesi J (1994) The control of $\mathrm{Ca}^{2+}$ homeostasis: role of intracellular rapidly exchanging $\mathrm{Ca}^{2+}$ stores. Cell Biol Int Rep 18:301-307.

Villa A, Sharp AH, Racchetti G, Podini P, Bole DG, Dunn WA, Pozzan T, Snyder SH, Meldolesi J (1992) The endoplasmic reticulum of Purkinje neuron body and dendrites: molecular identity and specializations for $\mathrm{Ca}^{2+}$ transport. Neuroscience 49:467-477.

Westrum LE, Blackstad T (1962) An electron microscopic study of the stratum radiatum of the rat hippocampus (regio superior, CA1) with particular emphasis on synaptology. J Comp Neurol 119:281-309.

Westrum LE, Jones DH, Gray EG, Barron J (1980) Microtubules, dendritic spines and spine apparatuses. Cell tissue res 208:171-181.
Wickens J (1988) Electrically coupled but chemically isolated synapses: dendritic spines and calcium in a rule for synaptic modification. Prog Neurobiol 31:507-528.

Wilson CJ (1984) Passive cable properties of dendritic spines and spiny neurons. J Neurosci 4:281-297.

Woolf TB, Greer CA (1994) Local communication within dendritic spines: models of second messenger diffusion in granule cell spines of the mammalian olfactory bulb. Synapse 17:247-267.

Yuste R, Denk W (1995) Dendritic spines as basic functional units of neuronal integration. Nature 375:682-684.

Yuste R, Tank DW (1996) Dendritic integration in mammalian neurons, a century after Cajal. Neuron 16:701-716.

Zador A, Koch C, Brown TH (1990) Biophysical model of a Hebbian synapse. Proc Natl Acad Sci USA 87:6718-6722. 